\title{
Essay
}

\section{"Do I Need to Know This for the Exam?" Using Popular Media, Inquiry-based Laboratories, and a Community of Scientific Practice to Motivate Students to Learn Developmental Biology}

\author{
Marga Madhuri* and Christine Broussard ${ }^{\dagger}$
}

*Education Department, College of Education and Organizational Leadership and ${ }^{\dagger}$ Department of Biology, College of Arts and Sciences, University of La Verne, La Verne, CA 91750

Submitted July 2, 2007; Revised November 8, 2007; Accepted November 9, 2007

Monitoring Editor: Jeffrey Hardin

\begin{abstract}
One of the greatest challenges instructors face is getting students to connect with the subject in a manner that encourages them to learn. In this essay, we describe the redesign of our Developmental Biology course to foster a deeper connection between students and the field of developmental biology. In our approach, we created a community of scientific practice focused on the investigation of environmental impacts on embryonic development and informed by popular and scientific media, the students' own questions, and the instructor. Our goals were to engage students in meaningful ways with the material, to develop students' science process skills, and to enhance students' understanding of broad principles of developmental biology. Though significant challenges arose during implementation, assessments indicate using this approach to teach undergraduate developmental biology was successful.
\end{abstract}

\section{INTRODUCTION}

In the past 6 years the biology curriculum at the University of La Verne (ULV) has changed dramatically to address advances that have been made in biology, in our understanding of how students learn, and in what students need to know to be successful, informed citizens and scientists. According to the National Research Council (NRC; 2003), researchers in the twenty-first century must combine scientific knowledge, experimental design, quantitative analysis, and communication skills in order to be successful. In recent years, ULV biology faculty identified and implemented new (to us) approaches to better prepare our students for the challenges of the twenty-first century. Our primary concern was that although the study of biology had rapidly evolved over the last 20 years, the manner in which biology was taught at ULV had not. ULV biology majors had an appreciation for current scientific theory, but not current practices.

DOI: $10.1187 /$ cbe.07-06-0044

Address correspondence to: Christine Broussard (broussac@ ulv.edu).
This dissonance was of particular concern for the Developmental Biology course that C.B. was hired to teach. In previous years the Developmental Biology course had focused exclusively on descriptive aspects of developmental biology, such as the anatomical changes observed during development. However, ULV biology faculty recognized that curriculum change was required to integrate into the course experimental analysis, which has elucidated many of the underlying molecular and cellular processes that bring about anatomical changes.

We believed that integration of experimental analysis into the lecture and laboratory would benefit the students and enhance their learning. However, trading sets of slides for sets of expository lab experiments did not seem likely to motivate or excite students to learn developmental biology. Thus we set out to restructure the developmental biology experience in ways that developed students' skills in the process of science, while also engaging students in meaningful ways with the field. We elected to utilize popular books, journal club activities, and current events in the lecture sessions to enhance student learning, motivation, and investment in the material (NRC, 2000; 
Hofer, 2002). In the laboratory, we used inquiry-based learning and project-based laboratories to promote applied learning, retention, and skill in experimental design, execution, and communication (Coppola, 2002; Handelsman et al., 2004).

These aspects of the curriculum change were woven together into a semester-long "search for knowledge," a modification of the pedagogical strategy also known as Chèche Konnen that originated in 1987 (NRC, 2000; TERC, 2007). Chèche Konnen was developed to improve science education for struggling language-minority (Haitian) junior high and high school students in bilingual programs in Cambridge, MA. The foundation of this approach is the recognition that students already possess skills and knowledge that allow them to explore their environment. It utilizes the scientific method as a way to make sense of the everyday world. Students work together to ask questions, form hypotheses, test their hypotheses, and interpret the results. Teachers learn and develop professionally by participating in the inquiry process being guided by their students' interests, experiences, and needs. Reading about these scientific learning communities in secondary school science classes inspired us to translate this approach to higher education in developmental biology. In our revised Developmental Biology course, learning resulted from the creation of our own "community of scientific practice" (NRC, 2000) in which the discourse between the literature (scientific and popular), the students, the instructor, and the embryos uncovered basic principles governing development.

\section{THE DESIGN}

\section{The Population}

ULV is a not-for-profit, private liberal arts college, established in 1891, that serves approximately 1500 traditional undergraduates including $70 \%$ students of color, $38 \%$ firstin-family to attend college, and $86 \%$ receiving financial aid. ULV is classified as a Hispanic-Serving Institution because of the high proportion (33\%) of matriculating Hispanic students. The pool of incoming first-year students has an average high school GPA of 3.49 and an SAT score of 1000. ULV, as part of its mission, specifically targets students who score moderately on the SAT and demonstrate potential for success, but may not have had the resources or opportunities in secondary school to be better prepared for higher education. On average, 67 students (first year through senior year) are declared biology majors, including traditional-aged and CAPA (Campus Accelerated Program for Adults) students. Seventy-five percent of biology majors are women (ULV Fact Book, 2002-2006).

Developmental Biology is a required course for all biology majors and is usually taken after Cell Biology. The rationale for this sequence is that developmental biology emphasizes the cellular and molecular basis of the dynamic processes of embryogenesis. Therefore students must be grounded in cellular dynamics (form and function) to understand, master, and fully appreciate developmental biology. This sequence prepares the students for the theoretical concepts taught in the Developmental Biology course.
Fourteen students were enrolled in the class in Spring 2007 (two of the 14 had not taken Cell Biology). Although all 14 students had earned enough units to be classified as seniors, eight of the 14 had at least 1 year of course work remaining to complete their undergraduate degree requirements. The gender ratio was 50/50, seven women and seven men. Eleven of 14 were underrepresented minorities, predominantly Latino.

\section{Elements of the Lecture Design}

In C.B.'s experience teaching developmental biology, students invariably were more motivated at the end of the semester than at the beginning. Their motivation seemed to correlate with the introduction of human development and impacts of environmental factors on development. In restructuring the course, we sought to capitalize on this natural curiosity by incorporating human development and environmental impacts into the lecture portion of the course earlier in the semester (see Supplemental Material 1 for lecture and laboratory schedule). This was accomplished using two popular books, Having Faith: An Ecologist's Journey into Motherhood (Steingraber, 2001) and Our Stolen Future (Colborn et al., 1997). Students were assigned selected chapters from the books over the course of the semester. Having Faith was selected not only because it was written as a popular book, but also because it traces the pregnancy experience of the author, a college professor. Interspersed in the pregnancy narrative are science vignettes addressing well-known environmental toxicants such as lead and mercury, as well as other chemicals that impact development. Important concepts like threshold of exposure, the myth of the placental barrier, and the precautionary principle are covered as well.

Our Stolen Future, on the other hand, introduces effects of environmental toxicants on wildlife. It focuses on the class of molecules termed endocrine disruptors. These molecules mimic, block, or inhibit synthesis of hormones (Colborn et al., 1997). By surveying the primary literature on a variety of organisms and endocrine disruptors, Colborn et al. build a solid case suggesting that the reproductive fitness and health of the entire ecosystem, including humans, is being impacted by these chemicals.

The inclusion of the popular books into the lecture caused students to consider the impact of environmental toxicants on human development. For example one student wrote, "The author [of Our Stolen Future] creates an awareness and forces us to pay close attention. Even more significant, is the way that these problems seem to become more personal after the readings. Rather than the common belief that the problem doesn't affect you, the author places you in the middle of the discussion and urges you to make the right decisions before it becomes too late." A second student wrote, "I never though [sic] that something in ppb [parts per billion] could have such developmental defects [sic] on a developing fetus. Reading Having Faith really drilled that point in my head." A third student wrote, "Having Faith made me think about the future, what is affecting our bodies now? We shouldn't wait and see, we should question what we consume." A fourth student wrote, "... when I chose [sic] to have babies of my own I will be cautious about what I put in my mouth." 
Although C.B. was concerned that students would not read the popular texts critically and perhaps come away from the course believing that everything around us was dangerous to development, the students showed proof of their critical thinking through their journal responses. For example one student wrote in an essay, "We cannot prevent everything from harming us. . . an important concept emphasized in Our Stolen Future was for us to. . . have them [manufacturers of consumer products and chemicals, e.g., plastics and pesticides] show significant scientific evidence that their products (or byproducts) are environmentally safe." A second student wrote, "One concern I had. . . was that. . . the book [Our Stolen Future] was trying to persuade the reader that everything can be harmful... I just don't think that having a book that spreads fear is a good method of informing the public." The students' ability to analyze, question, and critique the popular readings led to lively discussions that allowed us to delve further into the issues facing scientists and the community at large.

To give the students an opportunity to critique scientific literature evaluating developmental toxicants, we also asked students to comb through the current literature for primary papers addressing the impact of environmental toxicants on development. Groups of three students presented a paper of their choice. Students were evaluated on their ability to relay appropriate background material, to effectively explain the data, and to critically evaluate the work. The presentations were scheduled so that the topic dove-tailed with material covered in class. For example, a paper on effects of alcohol exposure on fetal eye development was presented after aspects of eye development were discussed in class.

A final element used in the lecture portion of the course was a video of a lecture, "From Silent Spring to Silent Night," delivered by biologist and herpetologist Tyrone Hayes in March 2007 and accessed through YouTube (Hayes, 2007). This lecture is an overview of Dr. Hayes' work in the lab and in the field examining the effects of atrazine, an agricultural pesticide, on frog development. The first half of the lecture deals exclusively with his work on frogs, whereas the second half of the lecture extrapolates his work to other organisms and humans. The lecture is informative and entertaining. It covers scientific method and laboratory versus field approaches, as well as reviews the work of others in the field. The lecture is controversial because of the antagonistic relationship that has developed between Syngenta (the parent company that makes atrazine), the Environmental Protection Agency, and Dr. Hayes (whose research was formerly funded by Syngenta). It also deals with a current environmental impact, as the lecture was given just before a state hearing on banning the use of atrazine. By using technology coupled with important current events, students became engaged in the topic and understood its relevance.

\section{Assessment of Lecture Design}

Assessment of student understanding of the popular readings and video was accomplished using discussion and reflection activities. These assessment tools had been used in a nonmajors' environmental science class taught by C.B., but have not generally been used in majors' biology classes.
These types of activities seemed appropriate considering our goal for adding the material was to motivate students to learn and to become more invested in developmental biology. Instead of testing knowledge and comprehension, we wanted to know if the students had analyzed, synthesized, and evaluated the material (Bloom, 1956). Furthermore, we wanted to determine if the students applied the information to their own lives and to the material covered in the primary text for the class, Developmental Biology, 8th ed. (Gilbert, 2006).

Students fared well on the reflection and discussion activities, averaging 93.4\%, compared with multiple choice, short answer, and essays on lecture material, where the average was $74 \%$. For reflection and discussion assessments, students were evaluated on the thoroughness and thoughtfulness of their answers and the ability to support their point of view based on the readings. In the previous iteration (Spring 2006) of the course, in which only the Having Faith readings were included, average scores were 87.5\% for reflection and $75 \%$ for multiple choice, short answer, and essays on lecture material.

Evidence that the students applied the readings to their own experience came from the reflection essays. One student shared that as a youth her father worked in cotton fields where pesticides were sprayed from planes while he was picking cotton. The runoff contaminated a river where the workers obtained drinking water. She wondered if her father's health problems were due in part to his exposure to these pesticides. Another student wrote, "After reading Our Stolen Future, I applied what I learned from that book. . . it made me pay closer attention to the habits I had whether recycling. . . or informing others of the dangers that exist in water." A third student wrote that he was unaware that plasticizers leached out of plastics when heated. After learning about this, he vowed to microwave food for his 2-yr-old son in nonplastic containers.

\section{Elements of the Laboratory Design}

Inquiry- and problem-based learning have been shown to promote learning, retention, and development of science process skills (NRC, 2000, 2003; Coppola, 2002). Although current science pedagogy and policy recommend that all students become involved in the practice and excitement of science by direct inquiry-based experience as early as possible in the undergraduate curriculum (National Science Foundation, 1996, 1999; Boyer Report, 1998; Handelsman et al., 2004), the majority of biology courses with laboratory components at ULV used this pedagogy in a limited manner. Our goal was to embed inquiry-based learning into the foundation of the laboratory experience for developmental biology.

In our redesign of the lab we considered feedback (formative assessment; NRC, 2000) from students regarding the challenges and perceptions that might promote or prevent them from taking full advantage of the curriculum change. Of particular concern was how students would react to laboratory activities that had no defined results, that is, open-ended experimentation. We found that the students were comfortable with having novel results, but were uncomfortable when they did not know what the process was. Open-ended experimentation was acceptable if they were clear on process. 
We considered other comments students made regarding their lab experiences as well, including the following:

"We read research papers/articles and if we've done the techniques in lab it helps us know what they're talking about."

"In [another lab] we had to memorize genus/species that was a waste. Never felt like we applied that."

"I get really motivated when I know that it's going to apply to what I've learned in the course (e.g., learning about an organism and then doing an experiment with it)."

"When a lab is relevant to me personally or professionally, I'm much more motivated."

The laboratory experience was modeled after the Marine Biological Laboratory's Embryology Course (Marine Biological Laboratory, 2007). We used an organism-byorganism approach in which each model system was selected to emphasize a common theme in development (see Supplemental Material 1 for lecture and laboratory schedule). Sea urchin embryos were studied as a model for fertilization, cell activation, and cleavage. Frogs were selected to study gastrulation and neurulation events. Drosophila embryos were used to study gene cascades in development, whereas chick embryos were used to study organogenesis.

The first week or two of each module students learned about the model organism. We typically performed a preset experiment to determine optimal conditions for growth (e.g., sea urchins) or to learn techniques (e.g., windowing, embryo culture, and shell-less egg culture for chick embryos). Once students mastered working with the organism and techniques, we shifted to an inquiry-based approach. Pairs of students researched an experimental question of interest to them. The theme of the proposals was an investigation of the effects of environmental toxicants on some aspect of development of the current organism. Students were required to look up relevant references and submit an experimental proposal for their research. Suggestions for experiments were provided (laboratory module handouts; Tyler and Kozlowski, 2003), but students were strongly encouraged to modify these to ask an original question.

The proposals contained introductory information, including the experimental question the students wanted to address and their hypothesis, the necessary materials, the experimental design, and references (see Box 1 ).

Proposals were submitted in advance and then discussed in an open forum during a lab session. The students, lab manager, and C.B. critiqued each proposal to strengthen the students' designs and to determine whether the equipment and reagents required for each proposal were available. Revised proposals were resubmitted for grading. This discussion provided opportunities for students to examine their thinking (NRC, 2000) about the process of science and to make better decisions in future designs. The transparency of their thinking also provided an opportunity for C.B. to correct, coach, and model experimental design.
Box 1. An Example of the Design-Your-Own Experiment Proposal

\section{Experimental Design}

The purpose of this experiment is to determine the effects of increasing amounts of copper on the embryonic development of Stonglyocentrotus franciscans. Copper was chosen for this experiment because a previous study found that copper is more toxic to embryo development than was cadmium, lead, and zinc (King and Riddle, 2001). Furthermore, in 1988 a copper ore ship sank of [sic] the coast of California which resulted in copper existing a hundred times more than normal in the area of the spill [sic]. This led to a documented decrease in the viability of sea urchins in that area (New York Times, 1988). Research has indicated that copper effects[sic] the development of sea urchins by demonstrating spinal closure, loss of spines, and changes of the fluid $\mathrm{pH}$ in the coelom (Bielmyer et al., 2005). Furthermore, another study showed that the effects of copper are more prominent in the developing embryo at gastrulation than at first cleavage and blastula formation (Kobayashi and Okamura, 2002). Exposure to large amounts of copper has also been researched, and results indicate that copper slows the rate of mitosis in the embryo (Palumbi, 2004). This study will focus on the abnormal development of sea urchin embryos caused by addition of copper to the embryo's environment. Separate groups of sea urchin embryos will be exposed to increasing concentrations of copper. The effects of copper as a teratogen will be evaluated due to the high sensitivity of developing embryos to its environment.

This experiment will be conducted by allowing normal fertilization in sea water solution without copper. Groups of 20 embryos will be designated to different concentrations of copper sulfate (copper sulfate will be used in place of pure copper). There will be a control group receiving no copper, and groups receiving concentrations of 20,40,60, 80, and 100 micrograms per liter of copper sulfate. These will all be kept at temperatures of $13-15^{\circ} \mathrm{C}$. Embryos will be exposed to copper treatments for four days. All treatments will be conducted in sea water of equal salinity, $\mathrm{pH}$, and temperature. They will be examined for viability and morphological abnormalities at increments of 24 , 48, 72, and 96 h. Each treatment will be replicated 3 times to ensure accurate and consistent results. Embryos will be observed using dissecting microscopes. Data will be analyzed using descriptive and inferential statistics to test for a significant difference between the normal development of the control group and that of the experimental groups.

\section{LITERATURE CITED}

Bielmyer, B. et al. (2005). The effects of metals on embryolarval and adult life stages of the sea urchin, Diadema antillarum. Aquatic Toxicol. 74, 254-263.

King, C., and Riddle, M. (2001). Effects of metal contaminants on the development of the common Antarctic sea urchin Sterechinus neumayeri and comparisons of sensitivity with tropical and temperate echinoids. Marine Ecol. 215, 143-154.

Kobayashi, N., and Okamura, H. (2002) Effects of new antifouling compounds on the development of sea urchin. Marine Pollution Bull. 44, 748-751.

Science Watch (1988, April 28). Copper in sea urchins. The New York Times Online. http://query.nytimes.com1 (accessed 15 March 2007).

Palumbi, L. (2004) The effects of toxins on sea urchin embryo development. Stanford University, unpublished presentation. 
The laboratory was officially scheduled to meet once a week for $2 \mathrm{~h}$ and $50 \mathrm{~min}$. However, student pairs carried out the experimentation on their own schedules, which were not necessarily within the scheduled lab periods. Indeed for some embryos and some stages of development being observed, it was not possible to set up and take down experiments in the regularly scheduled lab time.

After experimentation was completed, each student submitted a final report. Pairs shared data, but individuals wrote their own reports. The report followed the format of traditional primary papers: abstract, introduction, materials/methods, results, discussion, and references (Tyler and Kozlowski, 2003). In the introduction section, the students restated the experimental question, their hypothesis, and provided background information. The results section contained professionally prepared and accurate representations of the data in tables and/or graphs. Data were also explained in writing. In the discussion, students stated whether the data collected did or did not support the hypothesis and how the experimentation contributed to the broader field of development. These minimanuscript assignments (see Supplemental Material for an example) served three purposes. First, they gave the students the opportunity to synthesize what they had learned in the module. Second, they helped the students determine whether they had addressed their experimental question effectively. Third, they provided an opportunity to practice scientific communication.

This cycle-learning about the model organism, proposing a line of experimentation, carrying out the experiment, and writing about the results-was designed to be applied to each of the model organisms. However, challenges in acquiring gravid adults at the right time during the semester prevented using this approach with every animal. Students were able to employ this cycle with two model organisms, the sea urchin and the chick. At the end of the semester, the culminating activity in the laboratory was a poster session. Each student selected the experiment they thought went the best (i.e., gave them interpretable results and had appropriate controls). Though students had a partner for each module, partners were not required to present the same experiment for the poster session. One laboratory session was dedicated to effective poster design, and students had to submit their poster mockup for approval before undertaking the final poster. During the last laboratory session students presented their work to classmates and invited faculty members.

\section{Assessment of Laboratory Design}

In an effort to assess the impact of the design-your-own experiment (DYOE) format, we gave the students a survey with open-ended questions. Summarized below are the written comments relevant to the DYOE format.

1. How did being able to design and carry out your own experiments (as opposed to conducting preset experiments) affect your lab experience?

Five of the students wrote that the DYOE format enabled them to learn more about experimental techniques. Seven of the students wrote that the DYOE format made the lab more interesting, particularly because they wanted to find out their own results. Only one student did not enjoy the openended nature of the lab. However three of the students wrote that DYOE translated into more trial and error and increased stress when experiments were unsuccessful (Table 1).

2. Which concepts in the Developmental Biology course, if any, were easier to understand when you had the opportunity to work on them in a lab setting?

Seven of the students felt all concepts in the course were reinforced or easier to learn because of the lab experience. Five of the students felt some concepts were reinforced or easier to learn. Of the students who felt some concepts were reinforced or easier to learn, three specifically mentioned fertilization. Two of the students felt only the sensitivity of embryos and/or the impact of environmental toxicants on development were reinforced or easier to learn because of the lab (Table 2).

Students were also asked whether their mastery of developmental biology concepts occurred more effectively (compared with prior laboratory experiences) with the combined use of preset experiments and DYOE format. Thirteen of the students agreed that they mastered concepts more effectively with combined modalities. Of those 13, six strongly agreed and seven agreed. One of 14 students replied, "don't know."

Another way to determine the impact of the laboratory experience was to ask students about their senior project experience. The capstone experience of ULV biology majors is a two-semester independent research course, BIOL 499, in which students design, conduct, analyze, and present original research in written and oral form. In the past, approximately $75-80 \%$ of ULV biology majors were not completing their senior projects by their expected graduation date. The following open-ended question was included in the survey to assess the impact of the DYOE on senior projects.

3. Which concepts/aspects of completing your senior project, if any, were easier to understand after having the opportunity to design and carry out your own experiments in the developmental biology lab?

Table 1. Summary of impact of DYOE format on students' lab experience

\begin{tabular}{lc}
$\begin{array}{l}\text { How did DYOE format affect your } \\
\text { lab experience? }\end{array}$ & $\begin{array}{c}\text { No. of } \\
\text { respondents }\end{array}$ \\
\hline $\begin{array}{l}\text { Learned more about experimental } \\
\text { techniques }\end{array}$ & 5 \\
Made lab more interesting & 7 \\
More trial and error, more stress & 3 \\
Did not enjoy DYOE format & 1 \\
\hline a $\mathrm{n}=14$. \\
${ }^{\mathrm{b}}$ Respondents gave more than one answer; therefore the total num- \\
ber of responses is greater than 14.
\end{tabular}


Table 2. Summary of impact of DYOE format on students conceptual understanding of developmental biology

\begin{tabular}{lc}
$\begin{array}{c}\text { Developmental biology concepts easier to } \\
\text { understand when you had the opportunity } \\
\text { to work on them in the lab. }\end{array}$ & $\begin{array}{c}\text { No. of } \\
\text { respondents }\end{array}$ \\
\hline All & 7 \\
Some & 5 \\
Developmental sensitivity to toxicants & 2 \\
\hline${ }^{\mathrm{a}} \mathrm{n}=14$. & \\
\hline
\end{tabular}

Some students gave multiple answers to this question; therefore the number of responses is greater than the number of students in the course (Table 3). Students wrote that the DYOE format helped them to design their senior project experiments, to understand/carry out the techniques in their senior project, to analyze their senior project data, to interpret or draw conclusions from their data, and to understand the applications of their research. Three students indicated no concept/aspect was easier. Two students had completed their senior project before taking the Developmental Biology course and made no other comments.

The goals of the laboratory redesign were to develop students' science process skills and to enhance students' understanding of broad principles of developmental biology. One way to assess the achievement of these goals was to compare the laboratory performance and exam scores of students from the last 6 years, in which C.B. either co-taught the course or was the sole instructor (Table 4). Before 2004, the laboratory consisted entirely of expository laboratory activities. Starting in 2004, C.B. began integrating inquiry-based activities. Because of logistical considerations (see Discussion), the complete conversion of the lab to inquiry-based activities was not possible. However, even with a partial conversion of the lab to the
Table 3. Summary of impact of DYOE format on students senior project experience

\begin{tabular}{lc}
\hline \multicolumn{1}{c}{ Aspect of senior project made easier } & $\begin{array}{c}\text { No. of } \\
\text { respondents }\end{array}$ \\
\hline Research applications & 3 \\
Reading journal articles & 1 \\
Writing scientific papers & 3 \\
Designing experiments & 4 \\
Techniques & 5 \\
Analyzing data & 4 \\
Interpreting/drawing conclusions & 3 \\
None & 3 \\
Completed project before taking this course & 2 \\
\hline & \\
a $n=14$. & \\
b Respondents gave more than one answer; therefore the total num- \\
ber of responses is greater than the number of students in the \\
course.
\end{tabular}

inquiry-based approach, laboratory scores improved to an average of $85.8 \%$ (2004-2007), compared with $67.6 \%$ for years 2002 and 2003, in which an exclusively expository approach was used. Lecture exam scores did not appear to be appreciably different, averaging $74.8 \%$ with exclusively expository labs (2002 and 2003) and 75.1\% with inclusion of some inquiry-based labs (2004-2007). Analysis of laboratory and exam scores was complicated by the fact that the material in the lecture portion of the lab shifted from an anatomical and morphological focus to a cellular and molecular focus at the same time changes in the laboratory approach were being made.

To assess whether the goal of understanding basic principles of developmental biology was reached with this design, M.M. conducted a final focus group interview. During the interview, students wrote a reaction paper (see Box 2) and participated in a discussion. Students were asked to write about one main idea or theme worth remembering from the semester.

Table 4. Summary of average laboratory, exam, and reflection scores over the previous 6 years

\begin{tabular}{lrccrc}
\hline Year & $\mathrm{n}^{\mathrm{a}}$ & Inquiry-based elements & $\begin{array}{c}\text { Laboratory } \\
\text { scores }^{\mathrm{b}}\end{array}$ & $\begin{array}{c}\text { Exam scores } \\
{ }^{\mathrm{b}}\end{array}$ \\
\hline $2002^{\mathrm{c}}$ & 12 & No & $72.14 \pm 12.48$ & $72.72 \pm 18.83$ & $\mathrm{~N} / \mathrm{A}$ \\
$2003^{\mathrm{c}}$ & 9 & No & $63.11 \pm 19.25$ & $76.94 \pm 12.30$ & $\mathrm{~N} / \mathrm{A}$ \\
$2004^{\mathrm{c}}$ & 12 & Some & $86.06 \pm 12.44$ & $81.17 \pm 16.65$ & $\mathrm{~N} / \mathrm{A}$ \\
$2005^{\mathrm{d}}$ & 15 & Some & $90.09 \pm 6.24$ & $70.05 \pm 19.24$ & $\mathrm{~N} / \mathrm{A}$ \\
$2006^{\mathrm{e}}$ & 9 & Some & $86.33 \pm 7.01$ & $74.97 \pm 13.66$ & $87.50 \pm 7.23^{\mathrm{f}}$ \\
$2007^{\mathrm{e}}$ & 14 & Some & $80.89 \pm 9.23$ & $74.01 \pm 15.84$ & $93.42 \pm 8.09$ \\
\hline
\end{tabular}

${ }^{a}$ Number of students completing all assignments and exams.

${ }^{\mathrm{b}}$ Average score as a percent of $100 \pm \mathrm{SD}$. N/A, not applicable.

${ }^{\mathrm{C}}$ C.B. was co-instructor.

${ }^{\mathrm{d}}$ C.B. was on maternity leave two-thirds of the semester.

e C.B. was sole instructor.

${ }^{\mathrm{f}} \mathrm{n}=8$. One student did not participate in reflection assignments, but completed all other assignments. 
Box 2. Reaction Paper Guidelines, Based in part on Christensen, 2000

\section{University of La Verne BIOL 313 Developmental Biology, Spring 2007, Student Feedback}

Write a Reaction Paper. A reaction paper gives you the opportunity to discuss your experience and thoughts about the class and lab projects. The paper should cover both your experience in class and the laboratory. Take 10 or 15 minutes. When you are done we will discuss everyone's responses as a group. (I will type up a report based on your papers and our discussion. The report will be submitted to Dr. Broussard after semester grades have been submitted on June 4th. Your honesty and constructive thoughts are greatly appreciated.)

Your paper should consist of the following parts:

"Keeper" = 1 main idea or theme from the semester that is worth remembering

"Query" = 1 problem you had, question for the instructor, or criticism of the course (class and/or lab)

"Aha!" = specific point that made you stop and think, or have an unexpected realization

"So What?" = an evaluation of the significance or impact of this course on your future/career plans. Note that significance is not the same as a summaryyou need to explain why this experience was important, not simply summarize what you did.

The following are excerpts from student papers:

“... the developmental process is very complex but follows main principles that are similar to other organisms... our environment affects this development."

"... the intricate Web of processes that occur [sic] during the stages of development of many different organisms. The fate of an embryo is dictated by numerous processes (genes being activated/inhibited; cascades of gene transcription etc.) . . . all of which can be altered by minute [concentrations] of environmental toxicants. .."

"This course has allowed me to appreciate the mechanisms involved in developing embryos... many organisms share common proteins and/or pathways during embryogenesis... The Having Faith reading and the atrazine video allowed me to observe how humans and animals are exposed to toxicants on a persistent level. One cannot understand the effects of these materials until one appreciates the intricate mechanisms involved in organismal development."

\section{DISCUSSION}

Challenges arose in implementing the described curriculum change from both the student and instructor perspective. A significant challenge was handling the logistics of guiding students through actual research projects. Both students and C.B. noted the intensive time required to carry out the DYOE format. Students had to be in lab multiple times per week instead of the scheduled one afternoon per week. Four of 11 students wrote in the final interview reaction paper that the lab took too much time. C.B. had to be available for each group coming in to set up or collect data from experiments. It was rare for more than two groups to overlap. Space conflicts also arose as a result of the laboratory space being used by two laboratory classes and for other research projects.

Another challenge was obtaining quality embryos and reagents in a timely manner. Four of 11 students wrote that the quality and availability of embryos was an issue of concern. Originally, the plan for the lab was to use sea urchins, frogs, and chicks. However, the biology department was unable to obtain frogs because of weather conditions at the collection site. By the time the animals were available, this module conflicted with spring break and subsequent lab activities. It became necessary to create a new module with only a week's notice. We elected to guide the students through a module investigating Drosophila embryo development using immunohistochemistry techniques. We had stained and unstained embryos for students to use, but no live flies or embryos. This allowed the students to study syncytial development and gene expression cascades, but provided limited opportunities to apply the DYOE format.

A third challenge that impacted the success of the course was the limited equipment available. When this course was taught, ULV lacked many modern and standard pieces of equipment found in developmental biology laboratories such as fluorescence microscopes, microinjection or microsurgical equipment, and digital cameras for recording images from the microscopes. The lack of equipment limited the types and sophistication of experiments students could conduct. The goal was to encourage students to explore development experimentally on the cellular and molecular level; however, we lacked the tools to achieve this goal. The long-term plan was to secure grant funding to purchase equipment and reagents for cellular and molecular investigations. (These materials will be available when the course is taught again Spring 2008.)

To facilitate the student-led experimental approach in the short-term, we purchased dual-head stereomicroscopes, handheld digital cameras, and microscope adaptors (Martin Microscopes, Easley, SC). With these, students could photograph stained and unstained embryos using brightfield microscopy. Therefore, the majority of the data collected took the form of digital images taken with handheld digital cameras, quantification of morphological changes (including staining for apoptotic cells), and viability counts. Both C.B. and the students were unfamiliar with techniques to limit the size of the images. Thus data handling and timely feedback on reports were two important challenges as well. For students who did not have external key drives, transfer of data between partners, and between pairs of students and the instructor, was sometimes impossible.

A final challenge to the curriculum change process was standardizing the grading of student DYOE proposals and reports. It was necessary to define objectively what constituted a good piece of science writing in order for students to improve their skills in these activities. Rubrics for assessment of the DYOE assignment and final report were created using Rubistar (Rubistar, 2007), an online resource for teach- 
ers. This resource facilitated the correlation of levels of proficiency with numerical grades (see Table 5).

Even with the significant challenges we faced, the feedback from students exceeded our expectations. Our main goals were to motivate learning, increase investment in the topic, and develop skills in science process. Students demonstrated that they had applied, analyzed, synthesized, and evaluated (Bloom, 1956) the lecture material on administered assessments. Scores on the reflection assignments in 2007 (93.4\%) improved from the previous year's scores (87.5\% in 2006), suggesting that the current design of the course allowed students to connect with the material and apply what they were learning in the classroom and lab to their own lives (Table 4). Investment was demonstrated by full participation in the DYOE format and willingness to conduct experiments outside (and in addition to) regularly scheduled lab periods. Furthermore, students commonly referred to the lab work as "my" or "our" experiment. One student wrote, "I felt more like a scientist. . . contributing to the scientific community." Students also demonstrated their scientific skills in written (final reports) and oral (poster session) communications, averaging $80.9 \%$ on assessments of laboratory activities (compared with $63.1 \%$ in the 2003 iteration of the laboratory, which lacked any elements of the student-led experimental approach). These scores correlated with a mastery of basic science process skills.

It is clear from this limited retrospective analysis (Table 4), that the changes to the lecture and lab have improved laboratory performance, science process skills, and the ability of students to relate developmental biology to their own lives. What is unclear, however, is how effective these changes are in improving student exam scores and information reten- tion. Further analysis of the curriculum change after the incorporation of updated equipment and resources and complete conversion of the lab to inquiry-based modules may shed more light on the efficacy of the described approach in enhancing learning of basic concepts of developmental biology.

\section{Chèche Konnen: A Search for Knowledge}

Although the lecture portion of the course offered a more traditional trajectory of learning a set of material followed by an exam on that material, the popular books, journal clubs, and inquiry-based laboratory activities provided a continuous learning experience or thread that allowed the students to create, restructure, and share their knowledge of developmental biology over the course of the semester (NRC, 2000, 2003). The overall design of the Developmental Biology course was patterned after the Chèche Konnen scientific pedagogy model: the formation of a community of scientific practice (NRC, 2000; TERC, 2007). According to this model, students work in groups to pose their own questions, to construct hypotheses and to test them, to analyze and interpret data, and to share their findings with the class. In the process students develop communication skills, critical-thinking skills, and skills in scientific process, as well as an understanding of basic content. In our opinion, our results support the validity of applying this approach to developmental biology at the undergraduate level. Our strategy of using popular media and scientific literature, engaging students in inquiry-based laboratories, and building a community of scientific practice succeeded in motivat-

Table 5. Grading rubric for DYOE proposals

BIOL 313 Developmental Biology

Scientific concepts and purpose of the experiment (8 points)

Experimental design and data collection (8 points)

Information gathering (4 points)
The purpose of the lab or the question to be answered during the lab is clearly identified and stated. Explanations by group members indicate a clear and accurate understanding of scientific principles underlying the purpose and design.

Experimental design is logical with clear procedures and measurements. Data proposed to be taken several times in a careful, reliable manner.

Accurate information taken from several sources in a systematic manner.

Student pair names:

The purpose of the lab or the question to be answered during the lab is identified, but is stated in a somewhat unclear manner. Explanations by group members indicate a relatively accurate understanding of scientific principles underlying the purpose and design. Experimental design is logical with clear procedures and some clear measurements. Data proposed to be taken twice in a careful, reliable manner.

Accurate information taken from a couple of sources in a systematic manner.
The purpose of the lab or the question to be answered during the lab is partially identified, and is stated in a somewhat unclear manner. Explanations by group members indicate limited understanding of scientific principles underlying the purpose and design.

Experimental design is logical with some clear procedures and some clear measurements. Data proposed to be taken once in a careful, reliable manner.

Accurate information taken from a couple of sources but not systematically.
The purpose of the lab or the question to be answered during the lab is erroneous or irrelevant. Explanations by group members do not illustrate an understanding of scientific principles underlying the purpose and design.

Experimental design is not logical or does not contain any procedures or measurements. Data not proposed to be taken carefully or proposed to be taken in a unreliable manner.

Information taken from only one source and/or information not accurate.

Date created: January 21, 2004; date modified: March 7, 2007; the rubric made using RubiStar (http://rubistar.4teachers.org). 
ing learning, increasing investment in developmental biology, and helping students develop skills in science process.

\section{FUTURE PLANS}

Our efforts to update and innovate the developmental biology curriculum were part of a larger plan for curriculum innovation in biology. As another component of the larger plan, we applied for and were awarded funds from the National Science Foundation (NSF) Course, Curriculum, and Laboratory Improvement Program (Broussard, 2007). Funds from this program will be used to purchase additional equipment to provide students with experiences using modern techniques, to increase the scientific sophistication of the laboratory projects (including incorporating cellular and molecular techniques), and to apply this design to other courses including Cell Biology and other biology majors' and nonmajors' classes. We are also poised to collect longterm data tracking the progress of students to determine if this approach impacts retention, completion of the undergraduate degree in a timely manner, and pursuit of advanced degrees by underrepresented minorities in the sciences.

\section{ACKNOWLEDGMENTS}

We thank all of the students who participated in the Developmental Biology course, Pablo F. Weaver for managing the laboratory and review of the manuscript, Dr. Barbara Lom for helpful discussions, and Drs. Jeremy Korr and Kathleen F. Weaver for review of the manuscript. This work was supported in part by the NSF DUE 0632831, the College of Arts and Sciences, the College of Education, and the University of La Verne.

\section{REFERENCES}

Bloom, B. S. (ed.) (1956). Taxonomy of Educational Objectives, Handbook I: The Cognitive Domain, New York: Longman.

Boyer Report (1998). Reinventing Undergraduate Education: A Blueprint for America's Research Universities. The Boyer Commission on Educating Undergraduates in the Research University, Stony Brook, NY: Carnegie Foundation for the Advancement of Teaching.

Broussard, C. (2007). Visualizing Cells and Embryos: Integrating Modern Cell and Developmental Biology Techniques into the Undergraduate Biology Curriculum. National Science Foundation, Course, Curriculum and Laboratory Improvement, DUE 0632831.
Christensen, L. (2000). Reading, Writing, and Rising Up: Teaching About Social Justice and the Power of the Written Word, Rethinking Schools, Milwaukee, WI.

Colborn, T., Dumanoski, D., and Myers, J. P. (1997). Our Stolen Future. New York: Plume.

Coppola, B. P. (2002). Laboratory instruction: ensuring an active learning experience. McKeachie's Teaching Tips, 11th Ed., ed. W. McKeachie, Boston, MA: Houghton Mifflin, Chapter 19.

Gilbert, S. (ed.) (2006). Developmental Biology, 8th Ed., Sunderland, MA: Sinauer Associates.

Handelsman, J. et al.. (2004). Scientific teaching. Science 304, 521522.

Hayes, T. (2007). From Silent Spring to Silent Night. YouTube. http:/ / www.youtube.com/watch?v=z4lijvIjpRw (accessed 27 June 2007). Available for purchase at http://www.alteravista.org/ shows.html.

Hofer, B. (2002). Motivation in the college classroom. McKeachie's Teaching Tips, 11th Ed., ed. W. McKeachie, Boston, MA: Houghton Mifflin Company, Chapter 9.

Marine Biological Laboratory (2007). Embryology http://www. mbl.edu/education/courses/summer/course_embryo.html (accessed 28 June 2007).

National Research Council (NRC) (1999). Transforming Undergraduate Education in Science, Mathematics, Engineering, and Technology, Washington, DC: National Academies Press.

NRC (2000). How People Learn: Brain, Mind, Experience, and School, Washington, DC: National Academies Press.

NRC (2003). BIO 2010, Transforming Undergraduate Education for Future Research Biologists, Washington DC: National Academies Press.

National Science Foundation (1996). Shaping the Future: New Expectations for Undergraduate Education in Science, Mathematics, Engineering, and Technology. A Report on the Review of Undergraduate Education. (NSF 96-139). Arlington, VA.

Rubistar (2007). http://rubistar.4teachers.org/index.php (accessed 28 June 2007).

Steingraber, S. (2003). Having Faith: An Ecologist's Journey to Motherhood, New York: Berkley Books.

TERC (2007). Chèche Konnen Center: Science Teaching and Learning http://chechekonnen.terc.edu/ (accessed 28 June 2007).

Tyler, M. S., and Kozlowski, R. N. (2003). Vade Maecum². An Interactive Guide to Developmental Biology. Sunderland, MA: Sinauer Associates.

University of La Verne (2007). ULV Fact Book. (2006). www.ulv.edu/ir/reports/factbooks/fact_book_2002_06.pdf La Verne, CA (accessed 22 January 2007). 